\title{
Memetakan tautan budaya Lasem melalui dokumenter Net. biro Jawa Tengah dan MetroTVNews
}

\author{
Harry $^{1}$, Rustono Farady Marta ${ }^{2}$, Rizki Briandana ${ }^{3}$ \\ ${ }^{1}$ Universitas Bunda Mulia, Tangerang, Indonesia \\ ${ }^{2}$ Universitas Bunda Mulia, Jakarta, Indonesia \\ ${ }^{3}$ Universitas Mercu Buana, Jakarta, Indonesia
}

\begin{abstract}
ABSTRAK
Penanaman akulturasi budaya di Pulau Jawa telah terjalin sejak 600 tahun silam dan tertuangkan dalam video dokumenter. Penelitian ini bertujuan untuk membuktikan persatuan budaya di Kota Lasem, Jawa Tengah, melalui dua video dokumenter dari akun Net. Biro Jawa Tengah dan MetroTVNews menggunakan Analisis diskursus multimodalitas. Penelitian ini menggunakan teori Performa Kultural yang menjelaskan cara sebuah budaya merepresentasikan realita sosial, dan konsep Kishore yang menuturkan performa kultural dari video dokumenter digunakan sebagai media observasi realita sosial dalam penggunaan model visual, dan teori Metafora Visual yang membahas cara visual merajut makna atau ideologi kepada khalayak. Adapun metodologi yang digunakan adalah analisis teks dengan metode Multimodality Discourse Analysis. Objek penelitian ini mencakup dua video dokumenter Kota Lasem yang dipublikasi oleh dua akun yang berbeda, berupa Net. Biro Jawa Tengah dan MetroTVNews. Penelitian dilakukan dari bulan Januari hingga Mei 2021 dan dilakukan secara daring. Hasil penelitian menunjukkan bahwa kedua akun memiliki kesamaan ideologi dari pelestarian budaya Lasem berdasarkan jejak sejarah melalui karya seni. Ideologi ini juga mencerminkan perbedaan sudut pandang sineas pelaku komunikator pesan, dimana terdapat penciri khas dari karya seni yang ditayangkan. Net. Biro Jawa Tengah menampilkan Batik Tulis Lasem sebagai media konservasi budaya, sementara MetroTVNews menggunakan Tarian Tiga Warna sebagai model pelestarian budaya Lasem.
\end{abstract}

Kata-kata Kunci: Kota Lasem; budaya; dokumenter; multimodalitas; analisis teks

\section{Mapping Lasem's culture using documentary video on Net. Central Java bureau and MetroTVNews}

\begin{abstract}
The cultivation of cultural acculturation in Java has been established since 600 years ago and is stated in a documentary video. This study aims to prove cultural unity in Lasem City, Central Java, through two video documentaries, from Net. Central Java Bureau and MetroTVNews using multimodality discourse analysis. This study uses Cultural Performance theory which explains how a culture represents social reality, and the Kishore concept which describes the cultural performance from documentary videos is used as a medium to observe social reality on the use of visual model. Also, Visual Metaphor Theory which explains how visuals create meaning and ideology to the audiences. The methodology used is text analysis using the Multimodality Discourse Analysis. The object of this research includes two video documentaries of Lasem City, which were published by two different accounts, Net. Central Java Bureau and MetroTVNews. The study was conducted online from January to May 2021. The results of the study show that the two accounts share the same ideology of preserving Lasem culture based on historical traces through artworks. This ideology also reflects the different point of views of filmmakers as communicators of the messages, where characteristics of the artworks shown. Net. Central Java Bureau presented Lasem's Batik Tulis as a medium of cultural conservation, while MetroTVNews used the Three Colors Dance as a model of Lasem's culture preservation.
\end{abstract}

Keywords: Lasem; culture; documentary; multimodality; text analysis

Korespondensi: Harry, S.Sn. Universitas Bunda Mulia, UBM TOWER, Alam Sutera, Jl. Jalur Sutera Bar. No.Kav. 7, 9, RT.001/RW.015, Kunciran, Kec. Pinang, Kota Tangerang, Banten 15143. Email:harrykusno@ gmail.com 


\section{PENDAHULUAN}

Benih-benih toleransi antar umat di Pulau Jawa telah tertanam semenjak 600 tahun silam. Diawali dengan pelayaran dari sejumlah negara tetangga dan negara di belahan dunia lain yang bersimpangan dengan tanah air. Strategisnya wilayah Indonesia membuat proses pendaratan kapal dari negara yang berbeda, menjadikan Indonesia sebagai salah satu pusat perdagangan dan pertukaran budaya di Samudera Pasifik (Kurnianto \& Iswari, 2019). Hingga saat ini, tentunya kekuatan maritim Indonesia masih terasa oleh mata dunia (Kadek Yudiana et al., 2017).

Akulturasi budaya di Pulau Jawa masih menjadi pekerjaan rumah yang tak kunjung usai. Salah satu contohnya berupa jejak perjuangan Kerajaan Majapahit yang hampir berhasil mempersatukan Nusantara yang dikomandani oleh Mahapatih Gadjah Mada. Namun gugurnya beliau membuat faktor internal dan eksternal menumbangkan kerajaan Majapahit dan akulturasi budaya di Pulau Jawa harus dimulai dari titik nol kembali.

Etnis Tionghoa telah menetap di Pulau Jawa sejak abad ke-13, dengan konsentrasi terkuatnya berada di Kota Lasem. Rina Setyaningsih juga mengkonfirmasi bahwa agama Budha dan Hindu di Pulau Jawa telah masuk ke tanah air sebelum agama Islam mulai disebarkan setelah runtuhnya kerajaan Majapahit (Setyaningsih, 2020). Kota Lasem tersebut akhirnya menjadi pusat penanaman benih persatuan antar etnis di Pulau Jawa. Masyarakat di masa berikutnya menikmati hasil tuaian dari benih yang ditabur berabad-abad lamanya.

Mendaratnya Laksamana Cheng Ho di Pulau Jawa pada abad ke-13 menjadi peristiwa penting dalam akar persatuan etnis di Lasem, beliau menanamkan akar toleransi antar umat budaya di Indonesia yang variatif selama perjalanannya di Pulau Jawa. Terbukti juga dengan latar belakang Laksamana Cheng Ho sebagai seorang Muslim yang terlahir di Tiongkok dia tidak menyampingkan kebutuhan orang lain dari segi latar belakang. Sejumlah ajudan Laksamana Cheng Ho juga dikerahkan di berbagai titik Pulau Jawa untuk berbaur dan berdagang di tengah masyarakat Jawa, salah satunya di Kota Lasem.

Penanaman hibriditas budaya di Pulau Jawa berlanjut dalam peristiwa Perang Kuning atau Geger Pecinan yang menjadi saksi bisu unifikasi antara umat lokal Indonesia dengan umat Tionghoa dalam rangka melawan pendudukan kolonial Belanda dengan Kota Lasem sebagai pusat perlawanan. Pada perlawanan ini, lahir tiga pemimpin bernama Tan Kee Wie, Oee Ing Iat dan Raden Panji Margono. Berasal dari latar belakang yang berbeda, Raden Panji Margono memiliki musuh dan tujuan yang sama dengan 
kedua pemimpin dari etnis yang berbeda, berupa mengusir pemerintahan kolonial dari Pulau Jawa. Perlawanan berakhir dengan kekalahan, dimana ketiga pemimpin turut gugur dalam medan perang, namun peristiwa ini menjadi pilar berikutnya untuk Kota Lasem dalam mempersatukan kedua etnis yang berbeda.

Jasa patriotisme etnis Tionghoa di Indonesia juga terdokumentasi pada Perang Jawa pada tahun 1827-1828. Etnis Tionghoa di Pulau Jawa berkontribusi penuh terhadap sumber daya manusia dan perlengkapan perang untuk membela diri dari penjajah di tanah air (Setiono, 2008). Selain kontribusi tenaga manusia dan persenjataan, terlahir Pasukan Sasradilaga, yang dititis oleh Raden Tumenggung Sasradilaga, sebuah pasukan antar etnis yang memiliki satu tujuan, yaitu untuk membebaskan tanah air dari kolonialisme. Meskipun telah memberikan perlawanan sengit di berbagai wilayah pesisir utara seperti Rembang, Lasem dan Bojonegoro, penjajah mampu menumbangkan pasukan antar etnis ini dan dibantai tanpa pandang bulu.

Ketiga peristiwa tersebut menjadi kunci kukuhnya pencampuran budaya di Kota Lasem (Umarela et al., 2020). Kokohnya benteng hibriditas antara unsur budaya yang berbeda di Kota Lasem terbukti dari waktu-waktu ke depan. Hibriditas budaya Kota Lasem ini menunjukkan hasil keringat dari leluhur di Kota Lasem yang sukses menanamkan pencampuran unsur kultural kedalam masyarakatnya (Jatmiko, 2019).

Akulturasi budaya Kota Lasem ini kemudian dituangkan ke video dokumenter dari akun media sosial Youtube yang dapat dilihat publik. Video dokumenter ini menjadi ekspresi masyarakat Lasem yang memiliki hibriditas kultural yang tertuang kedalam sejumlah karya budaya (Fauzi \& Fasta, 2020).

Urgensi penguatan pluralisme kultural di Indonesia perlu disemboyankan kepada masyarakat sejak anak-anak (Sya et al., 2020). Teknik penanaman ideologi Bhineka Tunggal Ika sejak usia dini memberikan identitas kuat kepada anak yang tetap kukuh pada masa yang akan datang saat mereka mulai beranjak dewasa dan berbaur dengan komunitas. Saat ini penanaman ideologi Pancasila telah dibantu oleh perkembangan teknologi yang membuat teknik komunikator lebih menarik untuk khalayak seperti karakter kartun animasi.

Pembahasan latar belakang dalam paragraf diatas melahirkan sebuah ide penelitian untuk mengkaji dua video dokumenter yang menyampaikan campuran budaya di Kota Lasem. Adapun tujuan penelitian ini terlampir sebagai berikut: 1) Memetakan hibriditas kultural Kota Lasem dari video dokumenter akun Net. Biro Jawa Tengah berdasarkan perspektif multimodalitas; 2) Memetakan hibriditas kultural Kota Lasem dari video 
dokumenter akun MetroTVNews berdasarkan Perspektif Multimodalitas

Mendalami lebih jauh berkaitan pencampuran budaya Kota Lasem, peneliti mengeksplorasi sejumlah penelitian terdahulu untuk mendukung kajian hibriditas budaya Kota Lasem dalam penelitian ini. Mawalia dalam penelitiannya menemukan adaptasi mahasiswa Madura yang menuntut ilmu di Yogyakarta sebagai salah satu teknik untuk berbaur dalam komunitas (Mawalia \& Sanityastuti, 2020). Hal ini menunjukkan pencampuran budaya tidak hanya dalam skala besar, namun juga dapat terjalin dalam skala individu seperti gaya bicara, tata krama dan adat istiadat.

Penelitian yang mengkaji hibriditas kultural juga dilakukan di media cetak berupa Majalah GoGirls! yang menjadi jembatan perdamaian antara budaya lokal Indonesia dengan budaya barat (Utami \& Endah Sokowati, 2021). Penggabungan antar dua unsur budaya ini menciptakan sebuah identitas baru dalam sebuah media cetak yang menarik sejumlah pembaca.

Novtarianggi menemukan juga sebuah identitas campuran dalam karakter novel. Karakter dengan nama Darba ini menunjukkan identitas budaya timur dan budaya barat secara stimultan dan mencerminkan identitas karakter yang kebaruan dalam sebuah novel (Novtarianggi et al., 2020).
Beralih kepada campuran unsur budaya dari segi suara. Sulistyo menemukan tiga aspek hibriditas dalam lirik lagu Suriname yang menjadi representasi Pascakolonial. Hibriditas, identitas dan kebangsaan menjadi aspek budaya yang kental dalam lirik untuk mengingatkan bangsa akan kolonialisme pada masa lampau (Sulistyo et al., 2020).

Hibriditas budaya juga tertuang dalam perempuan karir di Nusa Tenggara Timur yang tertuang kedalam sebuah video musik. Sebagai jembatan penghubung antar budaya NTT dengan budaya barat, musik lagu ini berperan penting untuk menyuarakan usaha perempuan karir tanpa menghilangkan unsur kebudayaan aslinya (Nafie, 2020). Unsur kultural NTT yang masih kental penting sebagai aspek penjembatanan antara video musik kepada khalayak lokal untuk mengapresiasi musik tersebut.

Museum juga menerapkan pencampuran ideologi budaya dalam merepresentasikan ruang kuasa. Sugiyanto menunjukkan bahwa terdapat perbedaan ideologi komunikator museum di Yogyakarta dalam merepresentasikan budaya Jawa dan budaya barat (Sugiyanto, 2021). Museum Sunobudoyo menggunakan identitas budaya timur sebagai sumber pengetahuan budaya, sementara Museum Keraton Yogyakarta menyelaraskan kedudukan budaya timur dengan budaya barat.

Hasil penelitian terdahulu berkaitan dengan 
campuran budaya yang terjabar di paragraf diatas menunjukkan pencampuran budaya dari timur dengan barat, namun tidak membahas pencampuran unsur budaya antar sesama budaya timur dengan unsur kultural yang berbeda. Penelitian ini akan mengeksplorasi hibriditas budaya timur antara budaya Jawa dengan budaya Tiongkok, menggunakan video dokumenter Kota Lasem sebagai ranah penelitian multimodalitas.

Terdapat dua teori untuk mendukung penelitian berbasis multimodalitas. Unsur teori ini nantinya akan digunakan untuk kajian visual maupun ideologi dari komunikator video dokumenter untuk menyampaikan pesan kepada khalayak (O’Halloran, 2008). Kedua teori tersebut adalah Visual Metaphor Theory dan Cultural Performance Theory.

Teori Metafora Visual membahas model visual yang merepresentasikan sebuah makna. Dimitriadis menjelaskan bahwa metafora digunakan sebagai penghubung dunia nyata dengan video visual. Teknik perekaman video dan pendalaman sensorik visual dapat membantu memperkuat metafora visual dalam menandakan sebuah pesan (Dimitriadis, 2020). Metafora visual tidak hanya sekedar mengkaji akan apa yang terlihat jelas oleh kasat mata, namun juga dapat diAnalisis berdasarkan auditorik dari dialog yang membahas sebuah visual (Latukolan et al., 2021). Untuk mencari simbol yang tidak terlihat, penting untuk peneliti dalam mencari identitas visual dalam video dokumenter (Habeahan et al., 2020). Adapun elemen dari teori Metafora Visual berupa Juxtaposition (JX), Fusion (FS) dan Replacement (RP) (Peterson et al., 2015).

Teori Performa Kultural akan menjelaskan cara sebuah budaya merepresentasikan realita sosial. Kishore menuturkan performa kultural dari video dokumenter digunakan sebagai media observasi realita sosial menggunakan model visual yang memiliki kajian teoritis (Kishore \& Stiff, 2020). Dari segi video dokumenter Kota Lasem, teori metafora visual akan membahas visualisasi dokumentasi karya budaya Kota Lasem. Makna yang dirajut melalui visual dan auditorik dapat mempengaruhi khalayak akan preservasi hibriditas kultural di Indonesia (Lumampauw et al., 2021). Elemen teori yang terdapat dari Performa Kultural terdiri dari Play (PLY), Poetic (POE) dan Power (PWR) (Littlejohn \& Foss, 2009)

Studi kasus dokumenter dapat menunjukkan bagaimana berbagai teknik produksi, gaya penyutradaraan, kemitraan nirlaba, dan keterlibatan audiens telah bekerja dengan baik dalam beberapa kasus, dan tidak begitu baik dalam kasus lain (Rosenthal \& Eckhardt, 2016). Video advokasi dokumenter yang sadar sosial seperti Blue Vinyl karya Judith Helfand dan Waiting for "Superman" karya 
Davis Guggenheim dibuat untuk memberi tahu penonton tentang potensi kesalahan serta untuk merangsang perubahan, yang keduanya lakukan.

Ideologi komunikan dalam video dokumenter dirajut untuk memberikan pengetahuan kepada khalayak. Teknik visual dan performatik budaya menjadi faktor utama dalam konstruksi ideologi kepada khalayak, seperti yang diungkapkan Marta dan Robin dimana dalam komunikasi pemasaran BNI, terajut ideologi kekeluargaan untuk program pemasaran bank yang mendapatkan respon efektif kepada khalayak (Marta \& Robin, 2019).

Kajian video dokumenter tentunya bukan kali pertama dalam penelitian ini. Perdana(2020) menganalisis video dokumenter "Sexy Killer" yang menuai banyak kontroversi pada waktu yang bersangkutan. Disana dia menemukan makna dominasi pemerintah dan pelaku usaha yang berdampak langsung terhadap kehidupan rakyat di wilayah tambang mineral di Indonesia (Perdana, 2020).

Dalam analisis komparatif dua video dokumenter menemukan realita sosial masyarakat Samin yang menentang pembangunan pabrik Semen di wilayah mereka. Selain itu juga ditemukan bahwa kedua video dokumenter tidak bermaksud memberikan pesan propaganda kepada khalayak, meskipun memiliki konteks yang berbeda (Fajri, 2020).
Video dokumenter Dalae dan Beut Ba'da Meugreb yang dikaji Mahlil (2020) mengandung unsur penyebaran agama Islam di Provinsi Aceh. Kedua video dokumenter ini juga diharapkan mampu menjadi media pelestarian nilai keagamaan di Aceh pada masa yang akan datang (Mahlil, 2020). Terdapat juga Analisis video dokumenter dari program televisi National Geographic dari Hong (2020), dimana dia menemukan makna naratif, representatif dan interaktif dalam adegan visual video dokumenter terkait konstruksi merek wilayah Sichuan (Hong \& Duan, 2020).

Analisis video dokumenter Sri Lanka berjudul "Demons in Paradise" yang dikonduksi Premaratna (2020), terlihat juga makna visual untuk menjaga perdamaian bangsa Sri Lanka (Premaratna, 2021). Sementara itu, video dokumenter juga dapat memberikan makna rasa takut kepada khalayak, seperti video dokumenter yang dikaji Mliless (2020). Kajian video dokumenter Moroko, terdapat implikasi dari pemerintah dan non-pemerintah dalam menyampaikan pesan kerusakan pantai Sidi Boughaba yang sudah berdampak fatal kepada kondisi ekologi di wilayah pantai tersebut (Mliless \& Azzouzi, 2020).

Dalam konteks ini, dokumenter berurusan secara eksklusif dengan fakta dan peristiwa kehidupan nyata (Bernard, 2010; Hepler, 2012). Representasi dari kehidupan nyata yang 
tertuang dalam video dokumenter menjadi aspek perancangan ideologi dari sineas kepada khalayak.

Tujuan utama dari sebuah video dokumenter adalah untuk menginformasikan dan mendidik (Kuo, 2012). Sehingga apa yang dipaparkan dalam dua dokumenter ini perlu ditelaah lebih jauh. Dokumenter memiliki sejarah panjang dan kokoh yang berlabuh dalam upaya untuk menyebarluaskan, pada skala regional, nasional, dan internasional, "kebenaran" tentang topiktopik kepentingan publik (Hepler, 2012). Tidak semua video nonfiksi memiliki tujuan akhir dari perubahan sosial langsung, karena subgenre dari kategori ini secara sistematis berkisar dari puitis dan ekspositori hingga performatif dan partisipatif (Bernard, 2010).

Berdasarkan uraian penelitian yang telah dilakukan sebelumnya, penelitian ini akan membahas dua video dokumenter dengan konteks budaya, dimana kedua video dokumenter terekstrak dari dua program televisi di Indonesia yang berbeda.

\section{METODE PENELITIAN}

Penelitian yang dikonduksi berjenis kualitatif dengan paradigma konstruktivis. Perspektif tradisi semiotika digunakan mengingat penelitian ini mencakup analisis teks dengan metode Multimodality Discourse Analysis. Objek penelitian ini mencakup dua

video dokumenter Kota Lasem yang dipublikasi oleh dua akun yang berbeda, berupa Net. Biro Jawa Tengah dan MetroTVNews. Penelitian dilakukan dari bulan Januari hingga Mei 2021 dan dilakukan secara daring.

Sebelum memulai proses penelitian, terdapat tahapan awal yang dibutuhkan untuk mengelaborasi lebih jauh akan teknik kajian dalam penelitian ini. Analisis video dokumenter dengan pemikiran multimodalitas membutuhkan dua elemen teori dari Visual Metaphor Theory dan Cultural Performance Theory dengan pemetaan teori pada Tabel 1 dan Tabel 2.

Tabel 1 Pemetaan Elemen Visual Metaphor Theory

Elemen

\begin{tabular}{cc}
\hline Juxtaposition (JX) & $\begin{array}{c}\text { Objek dan Latar Belakang tidak } \\
\text { sinergis namum masih berinteraksi }\end{array}$ \\
Fusion (FS) & $\begin{array}{c}\text { Sinergi antara Objek dengan Latar } \\
\text { Belakang untuk membuat makna } \\
\text { Indikasi ada salah satu kategori yang } \\
\text { menghilang antara objek atau latar } \\
\text { belakang }\end{array}$ \\
\hline
\end{tabular}

Sumber: Hasil Olahan Peneliti, 2021

Tabel 2 Pemetaan Elemen Cultural Performance Theory

\begin{tabular}{cc}
\hline Elemen & Definisi \\
\hline Play (PLY) & $\begin{array}{c}\text { Makna dirancang dari pengalaman } \\
\text { performatif sehari-hari }\end{array}$ \\
Poetic (POE) & $\begin{array}{c}\text { Makna dirancang dari pengalaman } \\
\text { simbolik melalui budaya }\end{array}$ \\
Power $($ PWR $)$ & $\begin{array}{c}\text { Makna dirancang dari indikasi } \\
\text { kelompok yang tertindas }\end{array}$ \\
\hline
\end{tabular}

Sumber: Hasil Olahan Peneliti, 2021 
Data dikumpulkan melalui pemetaan dua elemen teori, yaitu Visual Metaphor Theory dan Cultural Performance Theory, yang menjadi pedoman penelitian. Terdapat dua variasi pengumpulan data, dimana video dokumenter dari akun Net. Biro Jawa Tengah dan MetroTVNews sebagai objek penelitian.

Analisis data untuk penelitian berperspektif multimodalitas dapat dilakukan dengan sejumlah tahapan. Diawali dari pengumpulan data visual dari kedua objek penelitian yang berkaitan, penelitian ini akan menggunakan kedua elemen teori yang dijabarkan dalam kode untuk mengidentifikasi tingkatan visual dan budaya yang ditampilkan dalam video Dokumenter. Instrumen penelitian ini menggunakan Multimodalitas dari O’Halloran dan uji keabsahan data dalam penelitian ini akan menggunakan teknik triangulasi (O'Halloran, 2011).

\section{HASIL DAN PEMBAHASAN}

Data penelitian secara umum menunjukkan model preservasi hibriditas budaya Kota Lasem dalam akun Net. Biro Jawa Tengah dan MetroTVNews. Perbedaan terdapat dalam ideologi komunikator kedua akun dalam merajut konservasi budaya Lasem kepada khalayak.

Berdasarkan hasil pemetaan awal dari pengumpulan data, dapat terlihat dari penelitian bahwa video dokumenter dari Net. Biro Jawa Tengah menunjukkan makna pelestarian budaya Lasem melalui Batik Tulis Lasem, sementara dokumentasi dari MetroTVNews mayoritas menunjukkan pelestarian budaya Lasem melalui Tarian Tiga Warna dengan teknik yang sama, yaitu melalui wawancara dengan tokoh yang terlibat dengan aktifitas pelestarian, dimana akun Net. Biro Jawa Tengah juga mendokumentasi aktifitas penulisan Batik Lasem di lapangan sebagai tambahan visual.

Video dokumenter Kota Lasem dari akun Net. Biro Jawa Tengah menyediakan Batik Tulis Lasem sebagai media pelestarian budaya Lasem, sementara video dokumenter dari akun MetroTVNews menggunakan Tarian Tiga Warna. Oleh karena itu peneliti mengkaji kedua video dengan tumpuan kedua model budaya sebagai wacana Multimodalitas.

Dimulai dari Analisis video dokumenter akun Net. Biro Jawa Tengah, terdapat gabungan antara dokumentasi aktifitas budaya di lapangan dengan wawancara tokoh yang terlibat dalam Batik Tulis Lasem. Analisis visual digabungkan melalui transkrip wawancara oleh tokoh bernama Maksum Ahadi, salah seorang pengrajin Batik Tulis Lasem.

Pembawa acara memperkenalkan khalayak akan Batik Tulis Lasem yang masih dilestarikan untuk perawalan video. Pada detik ke-41, muncul dokumentasi aktifitas Batik Tulis Lasem 
yang diiringi oleh musik dan dilanjutkan oleh wawancara Maksum sebagai narasumber, yang menandakan permulaan pemetaan elemen teori.

Semua adegan wawancara dalam video dokumenter ini hanya melibatkan narasumber yang menjawab pertanyaan. Makna visual dikaji berdasarkan transkrip wawancara dari narasumber. Di sisi lain ada salah satu adegan dokumentasi Batik Tulis Lasem yang berulang, yaitu pada durasi 01:41-02:04 dan 06:49-07:05 sehingga pemetaan visual digabungkan menjadi satu unit visual.

Kajian video dokumenter dari akun Net. Biro Jawa Tengah dimulai dari adegan dokumentasi Batik Tulis Lasem dimana model visual pertama menunjukkan salah satu pengrajin yang menulis detail Batik Tulis Lasem dengan kain batik sebagai objek fokus. Berdasarkan deskripsi visual dapat terlihat makna visual antara objek dengan pengrajin batik tulis yang sedang bekerja bersinergi untuk merajut makna pelestarian Batik Tulis Lasem (FS). Makna segi kultural dari model visual ini memberikan makna dari pengalaman pengrajin batik sehari-hari (PLY).

Model visual kedua menunjukkan seorang pengrajin batik yang merenggangkan kain batik tulis untuk dijemur sebagai objek utama perekaman. Terdapat pula kain batik yang telah dijemur sebagai objek sekunder dalam perekaman. Makna yang ditarik melalui deskripsi tayangan visual berupa kombinasi antara kain batik yang dijemur dengan berbagai motif untuk merancang pesan pelestarian Batik Tulis Lasem (FS). Kain batik yang memiliki motif dan warna yang berbeda merancang sebuah makna performatif budaya, dimana narasumber juga mengatakan bahwa warna merah yang lebih mencolok adalah pilar keunikan dari Batik Tulis Lasem (Farida et al., 2020).

Beralih ke tayangan visual ketiga dimana ditampilkan sekelompok pengrajin Batik Tulis Lasem yang masing-masing menulis motif batik dengan salah satu pengrajin sebagai objek utama perekaman. Peneliti menemukan interaksi antara pengrajin sebagai objek utama dengan pengrajin lainnya sebagai objek sekunder dalam merancang makna pelestarian Batik Tulis Lasem (JX). Makna pelestarian budaya Lasem juga tercerminkan melalui aktifitas sekelompok pengrajin batik yang menulis motif batik tersebut (PLY) (Hidayat et al., 2021).

Tayangan visual berikutnya menunjukkan kembali salah satu pengrajin batik tulis yang menulis motif batik secara lebih dekat, dengan pena tinta untuk penulisan motif batik sebagai objek utama dokumentasi. Peneliti melihat harmonisasi gerakan pena dalam merajut motif yang sekaligus menyampaikan makna visual dari adegan ini (FS). Selain itu konteks 
pengalaman performatif budaya juga terasa kental dengan motif batik (POE).

Model visual kelima menampilkan salah satu kain batik berwarna hitam dengan motif jingga dan merah yang dijemur untuk mensolidifikasi warna dan motif. Tidak terlihat ada kain batik lain dalam layar dokumentasi, namun ada seorang pengrajin batik yang berada di belakang layar sembari merenggangkan kain batik yang dijemur. Ada indikasi kain batik lain yang tidak ditampilkan dalam mengomposisian pesan budaya Lasem, namun adanya pengrajin batik yang tidak ditampilkan dalam layar karena tertutup kain batik yang dijemur masih dapat menyampaikan pesan kepada khalayak (RP). Teknik perekaman satu kain batik yang dekat juga diiringi oleh wawancara setelahnya menunjukkan permulaan dari indikasi kelompok pengrajin Batik Tulis Lasem yang berniat melestarikan batik Lasem karena popularitasnya yang dianggap belum dikenal khalayak luas pada waktu itu (PWR).

Tayangan visual keenam menampilkan sekelompok pengrajin batik yang menulis batik serupa dengan tayangan ketiga, dengan perspektif pendokumentasian yang berbeda. Di model visual ketiga terdapat satu pengrajin batik tulis yang lebih diprioritaskan sebagai objek utama dalam perekaman, sementara dalam tayangan visual ini menunjukkan aktifitas pengrajin batik secara keseluruhan. Perspektif dokumentasi yang berbeda juga merajut pesan visual yang berbeda, dimana layar visual ini menunjukkan sinergitas antar kelompok pengrajin batik yang masing-masing menulis motif batik (FS). Aktifitas harian dari pengrajin batik juga menyampaikan pesan pelestarian Batik Tulis Lasem dalam model visual ini. (PLY).

Dokumentasi visual terakhir menayangkan pengrajin batik dari visual keempat yang melanjutkan penulisan motif kain batik dengan perspektif yang berbeda. Dalam layar visual ini, tangan dan pena pengrajin batik menjadi fokus dalam pendokumentasian dengan representasi pengalaman budaya dari pengrajin dituangkan kedalam sebuah kain batik yang menyampaikan pesan kepada khalayak (POE). Makna visual yang ditarik juga mengindikasi interaksi antara pengrajin dengan pena dalam merancang motif batik tulis Lasem (JX) (Sasongko \& Marta, 2018)

Berdasarkan analisis visual dari dokumentasi lapangan oleh akun Net. Biro Jawa Tengah, dapat ditarik kesimpulan meskipun mayoritas metafora visual dirancang melalui sinergitas pengrajin batik dengan kain batik, masing-masing tayangan visual memiliki makna performatif budaya yang berbeda, dimana makna tersebut disesuaikan dengan konteks wawancara bersama Maksum sebagai narasumber dan tokoh yang terlibat dalam 
pelestarian Batik Tulis Lasem.

Kajian video dokumenter Kota Lasem dari akun Net. Biro Jawa Tengah dilanjutkan dengan adegan visual dari wawancara. Secara keseluruhan semua adegan wawancara hanya merekam narasumber yang menjawab sejumlah pertanyaan. Analisis metafora visual akan disesuaikan dengan transkrip wawancara yang telah diAnalisis peneliti.

Maksum dalam pertanyaan pertama menceritakan karakteristik Batik Tulis Lasem yang berada dalam motif dan warna merah dalam kain batik. Motif Batik Tulis Lasem tidak terikat dengan regulasi apapun sehingga pengrajin dapat berkreasi motif batik sesuai dengan kehendak pengrajin. Hal ini menunjukkan bahwa identitas Batik Tulis Lasem terdapat pada hasil komunikasi lintas budaya yang tertuang kepada kebebasan berkarya yang menjadikan Batik Tulis Lasem berbeda dari batik tulis di wilayah lain, sesuai yang diceritakan beliau dalam transkrip wawancara berikut (Kristianto \& Marta, 2019):

"Batik Lasem merupakan salah satu batik ukiran yang ada di pantai utara, dimana hampir secara umum pantai pesisiran mempunyai karakter warna, karakter batik yang hampir sama. Yaitu, batik pesisiran dominan dengan warna yang cerah atau kadangkala orang mengatakan cenderung jreng. Yang kedua masalah motif. kecenderungan batik pesisiran, mereka motif tanpa pakem, dalam artian tidak ada harus begini-begitu secara filosofi seperti apa yang ada di batik Solo. Sehingga mereka cenderung bebas berekspresi layaknya batik pekalongan, batik Madura, ataupun mungkin batik Tuban dan Cirebon."

Narasumber menjawab pertanyaan kedua dimana warna merah dalam kain batik Lasem yang mirip seperti janggut ayam menjadi nilai tersendiri bagi Batik Tulis Lasem. Motif Batik Tulis Lasem, meskipun tidak terikat dengan aturan apapun, umumnya didominasi oleh motif flora dan fauna, seperti yang diceritakan beliau dalam transkrip wawancara berikut:

"Salah satu kelebihan dan keunikan dari batik Lasem terdapat di warna merahnya, dimana karena kandungan zat yang ada di perairan Lasem, menyebabkan warna merah pada batik lain dengan yang lainnya. Merah Lasem memang cenderung orang bilang merah dara ayam, tapi kalau memang kita meruntut ke historinya, warna merah Lasem adalah merah mengkudu yang cenderung ke merah Batak. Disaat warna chemist itu datang, mereka baru mulai ada yang namanya merah jreng dan dara ayam yang seperti saat ini dibicarakan sebagai kelebihan dari batik Lasem itu sendiri. Yang Kedua, terkait dengan apa yang dimiliki Lasem, mereka mempunyai banyak hasanah budaya, flora maupun fauna, yang nantinya memberikan inspirasi pada pembatiknya terkait dengan desaindesain untuk pembentukan batik yang ada di Lasem itu."

Sejarah Batik Tulis Lasem pun dibahas dalam wawancara dengan Maksum dimana dia menjawab awal dari lahirnya Batik Tulis Lasem berada pada saat Laksamana Cheng Ho pulang ke Tuban dengan seorang pangeran berlatarbelakang Tiongkok dan seorang putri Bunangsih yang berasal dari Kota Lasem dengan keahlian membatik. Dari situlah budaya kerajinan batik 
diturunkan di Lasem dan juga Tiongkok yang sekaligus menjadi hasil akulturasi budaya Tiongkok dengan budaya Jawa. Lahirnya Batik Tulis Lasem menjadi seperti yang dijelaskan Maksum dalam transkrip berikut:

"Kalau batik berkembang di Lasem, banyak sejarah mengatakan disaat pula Laksamana Cheng Ho pulang ke Tuban dengan pasukannya ada seorang pangeran di Nang Un yang dengan seorang putri Bunangsih yang ada di Lasem yang disitu punya kegemaran untuk membatik dan disitu, mereka menularkan ilmu pembatikan yang dia miliki dari negeri China untuk batik di Lasem ini. Meskipun batik memang secara historis merupakan heritage dari Indonesia sendiri. Saya kira batik Lasem mungkin yang membedakan yang lain adalah adanya akulturasi budaya antara Jawa dan China. Itulah Batik Lasem."

Batik Tulis Lasem pada awalnya belum mencapai titik popularitas yang memuaskan. Terbukti pada tahun 2004 produksi Batik Tulis Lasem masih belum berkembang, meskipun masyarakat telah mengenal betul Batik Lasem. Menindaki kasus tersebut, Maksum beserta komunitas Jampu Awang Batikat memulai pelatihan untuk pewarnaan batik dari Dinas Pariwisata Provinsi. Sejak saat itu dimulailah akselerasi perkembangan Batik Tulis Lasem dan diperkuat pada saat kepemimpinan Bupati Lasem yang kedua, Mochamad Salim, dimana di tahun 2009 beliau membuat kegiatan berkaitan dengan Batik Tulis Lasem, seperti yang dijelaskan Maksum dalam transkrip berikut:

"Berikutnya masalah regenerasi pembatik memang, alhamdullilah, pemerintah Kabupaten Rembang mulai tahun 2009, utamanya, di era kepemimpinan Bapak Salim, Bupati kita yang kedua, itu sangat concern dan sangat serius menggarap batik ini, sehingga perkembangan untuk regenerasi ini sangat tinggi. Pertama, dengan adanya materi ekstrakulikuler sekolah diimplementasikan di dinas pendidikan sebagai muatan lokal. Tahun 2009, Bupati Salim mewacanakan adanya wisata-wisata batik."

Saat perekaman wawancara,-Maksum juga mengadaptasi tren zaman sekarang dimana program Go Green melahirkan komposisi warna alam kepada Batik Tulis Lasem tanpa menghilangkan identitas budaya Lasem dalam sebuah batik, seperti yang tertera dalam cuplikan wawancara berikut:

"Warna-warna klasik dari Lasem yang cenderung ngejreng, cenderung dominan dan sangat cerah, kita sekarang keluar mencoba untuk menambahkan warna pastel. Ataupun karena sekarang memang kita sedang mengarah ke go green, Lasem juga sudah mulai memunculkan batikbatik warna alam. Itu salah satu cara kita mensikapi kebutuhan dari masyarakat kekinian. Dalam kaitan bisnis yang namanya pengorbanan, perjuangan ataupun usaha yang tanpa henti, dengan inovasi dan kreatifitas serta daya serap terhadap apa yang semua orang inginkan dan miliki, itulah yang membuahkan sebuah karya Batik."

Melalui transkrip wawancara, Pak Maksum juga membuktikan bahwa pelestarian budaya tidak cukup hanya dengan usaha pengembangan aktifitas budaya, namun adaptasi dengan kebutuhan masyarakat saat ini menjadi penting 
untuk meningkatkan popularitas budaya, Beliau juga menuturkan bahwa dalam segala terutama di tengah maraknya budaya yang usaha, termasuk batik, pengorbanan, inovasi bervariasi di Indonesia (Sudarto et al., 2015). dan kreatifitas menjadi tiga kunci usaha yang

Tabel 3 Pemetaan Elemen Teori Video Dokumenter Kota Lasem dari Akun Net. Biro Jawa Tengah.

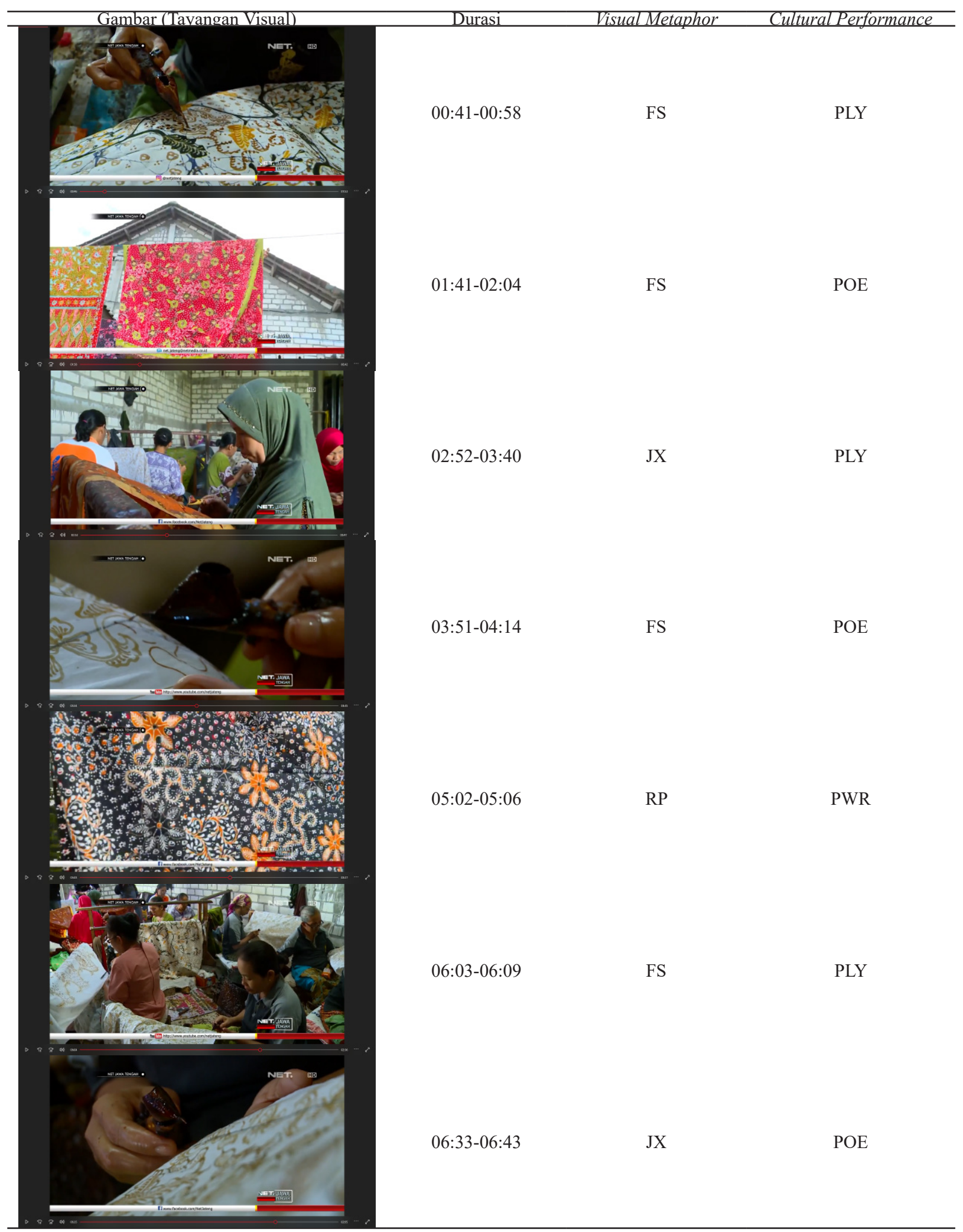

Sumber: Hasil Penelitian, 2021 
tidak dapat dihindari dan kemampuan untuk beradaptasi dengan perubahan penting untuk dilakoni setiap pelaku wirausaha.

Analisis secara keseluruhan menunjukkan keterpisahan transkrip wawancara dengan tayangan dokumentasi Batik Tulis Lasem di lapangan tidak menghalangi proses penyampaian pesan budaya Kota Lasem dari sebuah video dokumenter dan khalayak masih mampu menerima pesan pelestarian budaya Kota Lasem, baik dari segi budaya, sosial maupun ekonomi.

Berikut peneliti memetakan tayangan visual dokumentasi lapangan dalam Batik Tulis Lasem dari akun Net. Biro Jawa Tengah yang didasari oleh transkrip wawancara dengan Maksum sebagai narasumber dari video dokumenter:

Analisis video dokumenter Kota Lasem dilanjutkan menuju video yang dipublikasi oleh akun MetroTVNews yang berdurasi 2 menit 20 detik. Pengawal dari video dokumenter diputar hingga detik 43 dimana wawancara antara dua pewawancara dan dua narasumber dimulai. Selama wawancara berlangsung, narasumber pertama menjelaskan lahirnya nama "Tiga Warna" dari sebuah tarian memiliki makna sebagai tiga warna etnis dan kerukunan antar etnis di Lasem. Seperti yang tertera dari transkrip wawancara berikut:

"Saya lahir di Lasem. Pada saat saya sekolah mulai TK sampai SMP, saya sudah umum dengan tiga etnis di Lasem. Jadi muncul satu pelestarian melalui tarian. Pada saat itu saya ingin sekali melestarikan Lasem dengan kerukunannya. Tarian itu saya beri judul Tiga Warna, yang berarti warna kulit (Ras)"

Narasumber kedua menjelaskan makna dari tarian dan rentang usia, biasanya kalangan remaja, yang direkrut untuk menjadi penari, seperti yang tertera pada transkrip wawancara berikut:

"Kalau untuk tari tiga warna, saya mengambil usia remaja keatas. Karena dari tarian itu sudah harus menjiwai sikap kerukunan orang atau etnis. Jadi mampu menjiwai orang etnis tertentu seperti gimana, dan gerakan tarian itu diadaptasi dari kerukunan"

Kajian video dokumenter dari akun MetroTVNews dilanjutkan dengan analisis visual yang didasari oleh wawancara. Makna dari perekaman visual dapat tercipta berdasarkan transkrip wawancara yang mengindikasi topik yang dibicarakan.

Video ini tidak terlihat ada dokumentasi aktifitas Tarian Tiga Warna dalam tayangan visual manapun. Akun MetroTVNews membuat dokumentasi Tarian Tiga Warna menjadi sebuah peliputan wawancara untuk memberikan pesan kepada khalayak dalam rangka pelestarian budaya di Lasem. Video dokumenter ini termasuk unik jika dipandang dari segi visual mengingat makna visual umumnya dicerminkan dalam aktifitas budaya di Lasem. 
Berikut terlampir hasil pemetaan visual dari video dokumenter Kota Lasem dari akun MetroTVNews dalam bentuk tabel 4. Tayangan visual pertama dokumentasi difokuskan kepada Mochamad Salim yang bercerita latar belakang di balik berdirinya sanggar Tarian Tiga Warna dan cara Tarian Tiga Warna merepresentasikan kerukunan antar etnis di Lasem. Tayangan visual tidak menunjukkan dokumentasi tarian dan menunjukkan metafor replacement (RP) yang mengindikasikan ada objek yang tidak terlibat, meskipun layar visual dan wawancara menceritakan Tarian Tiga Warna dari Kota Lasem. Sementara transkrip wawancara menunjukkan makna sosial dari peliputan wawancara ini dari pengalaman budaya narasumber (POE).

Tayangan visual berikutnya menunjukkan peliputan wawancara terkait Tarian Tiga Warna secara keseluruhan dimana terjadi

Tabel 4 Pemetaan Elemen Teori Video Dokumenter Kota Lasem dari Akun MetroTVNews

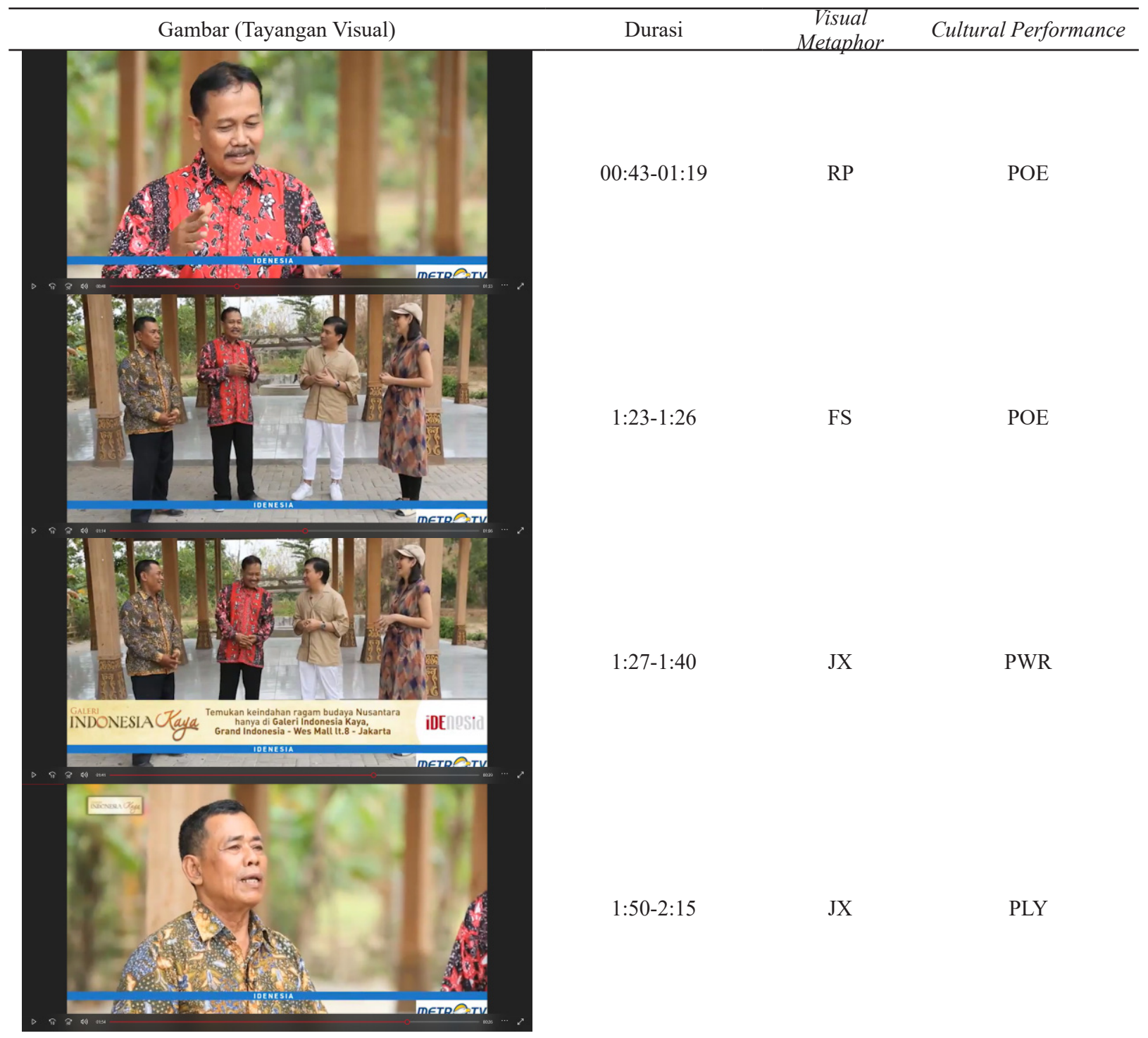

Sumber: Hasil Penelitian, 2021 
kelanjutan interaksi antara narasumber

dengan pewawancara. Disini pewawancara mengindikasikan makna Tarian Tiga Warna dari sebuah analogi yang menyebutkan tarian tersebut mirip dengan warna batik di Indonesia. Makna visual yang ditarik dari tayangan visual ini menunjukkan sinergitas dengan transkrip karena masing-masing narasumber mengenakan batik yang berbeda, meskipun kedua pewawancara tidak mengenakan batik (FS) (Castaldi, 2021). Representasi sosial yang ditunjukkan dari model visual dan transkrip wawancara juga menunjukkan adanya pengalaman budaya dari narasumber dan pewawancara dalam sesi ini (POE).

Model visual ketiga serupa dengan yang kedua namun dengan narasumber kedua ikut berpartisipasi dalam sesi wawancara sebagai perbedaannya. Diawali dengan narasumber pertama yang memperkenalkan narasumber kedua bernama Farlan yang disebut oleh narasumber pertama sebagai pakar tari dengan profesi pelatih tari di Lasem. Makna representasi sosial yang ditarik dari model visual ini menunjukkan perbedaan status dimana narasumber pertama membesarkan status narasumber kedua yang berkontribusi dengan sanggar tari di Lasem, meskipun tidak ada indikasi kelompok yang tertindas (PWR) (Saleh et al., 2020). Sementara makna visual yang diambil bukan merupakan sinergi seperti visual kedua, namun menunjukkan interaksi antar kedua narasumber yang terlihat cukup akrab (JX).

Tayangan visual terakhir menunjukkan Pak Farlan sebagai narasumber kedua yang melanjutkan jawaban dari narasumber pertama. Di adegan ini Farlan menjelaskan peserta yang berpartisipasi dalam sanggar Tarian Tiga Warna dan rentang usia peserta. Transkrip wawancara dapat menunjukkan realita sosial yang terkonstruksi dari pengalaman performatif sehari-hari, yang dalam kasus ini, berupa aktifitas peserta tarian tiga warna dan latar belakang peserta (PLY). Makna dari segi visual ini yang didasari transkrip wawancara bahwa tidak ada sinergi dari narasumber dengan konteks Tarian Tiga Warna namun masih menjelaskan aktifitas sanggar tari tersebut (JX).

Hasil Analisis dari video dokumenter dari akun MetroTVNews menunjukkan bahwa representasi budaya tidak perlu dokumentasi aktifitas budaya secara langsung, namun dapat dicerminkan melalui tokoh-tokoh yang terlibat dalam performa budaya yang dapat memberikan ideologi kerukunan kepada khalayak (Kurnianto \& Iswari, 2019).

\section{SIMPULAN}

Ideologi akun Net. Biro Jawa Tengah dalam menyampaikan campuran kultural Kota Lasem kepada khalayak ditunjukkan melalui Batik 
Tulis Lasem dan tokoh yang terlibat dalam pelestarian Batik Tulis Lasem.

Akun MetroTVNews menggunakan Tarian Tiga Warna sebagai model pelestarian hibriditas budaya Lasem kepada khalayak.

Hasil Analisis keseluruhan dari kedua akun menunjukkan terdapat perbedaan teknik visual yang digunakan untuk merajut ideologi kepada khalayak. Akun Net. Biro Jawa Tengah menggunakan dokumentasi langsung di lapangan yang disertai wawancara dengan tokoh yang terlibat dalam pelestarian Batik Tulis Lasem, sementara akun MetroTVNews menggunakan wawancara delapan mata dengan tokoh yang terlibat dalam pelestarian Tarian Tiga Warna sebagai teknik konstruksi ideologi kepada khalayak.

Penelitian ini memberikan sumbangsih ilmu hibriditas budaya timur antara Budaya Jawa dengan Budaya Tiongkok kepada masyarakat. Peneliti berharap masyarakat mampu mengapresiasi pencampuran unsur budaya dan dapat melahirkan campuran budaya baru serta melestarikan hibriditas kultural yang telah ada. Terakhir dan tidak terlupakan, peneliti berharap masyarakat dari seluruh Nusantara menurunkan ideologi hibriditas budaya kepada generasi mendatang mengingat pentingnya pemahaman akan perbedaan sebagai warga negara multikultural.

Tentunya, penelitian ini bukan tanpa keterbatasan. Keterbatasan pertama dalam penelitian ini berupa durasi kedua video dokumenter yang sangat jauh (8:40 untuk Net. Biro Jawa Tengah dengan 2:21 untuk MetroTVNews) karena dokumentasi budaya Kota Lasem terhitung masih terbatas. Keterbatasan berikutnya berupa komparasi visual yang berbeda, dimana akun Net. Biro Jawa Tengah mendokumentasi Batik Tulis Lasem sebagai model pelestarian budaya Lasem, sementara akun MetroTVNews mendokumentasi Tarian Tiga Warna sebagai budaya Lasem yang dilestarikan. Pencarian video dokumenter yang lebih mirip menjadi saran untuk penelitian ke depan yang melibatkan video dokumenter pada umumnya, dan video dokumenter pemetaan budaya pada khususnya.

\section{DAFTAR PUSTAKA}

Bernard, S. C. (2010). Documentary Story Telling. Focal Press.

Castaldi, J. (2021). A multimodal analysis of the representation of the Rohingya crisis in BBC's Burma with Simon Reeve (2018) : Integrating Audience Research in Multimodal Critical Discourse Studies . Multimodal Communication, 10(1), 55-72. https://doi.org/10.1515/mc-2020-0014

Dimitriadis, G. (2020). Immersion Through Culture: Representations of the "Day of the Dead" in Film. Revista Canaria de Estudios Ingleses, 81, 61-78. https://doi. org/10.25145/j.recaesin.2020.81.05

Fajri, N. C. (2020). Dualisme citra sedulur sikep dalam film dokumenter: analisis 
film "samin vs semen" dan "sikep samin semen." MEDIASI - Jurnal Kajian Dan Terapan Media, Bahasa, Komunikasi, 1(2), 124-135. https://doi.org/https://doi. org/10.46961/mediasi.v1i2.40

Farida, F., Zuklaiha, Z., \& Putro, H. E. (2020). Desentralisasi Wisata Religi Indonesia melalui City Branding Wisata Kabupaten Bangkalan Madura. Bricolage: Jurnal Magister Ilmu Komunikasi, 6, 224-234. https://doi.org/http://dx.doi.org/10.30813/ bricolage.v6i02.2149

Fauzi, E. P., \& Fasta, F. (2020). Modern Muslimah in Media: A Study of Reception Analysis in "Saliha" Program on Net TV. ASPIRATION, 1(November), 135-162.

Habeahan, M. A. G. K., Simanjuntak, R. F., \& Marta, R. F. (2020). Melampaui Kedirian Identitas Batak Melalui Ritual dan Sejarah Masyarakatnya Atas Inspirasi Levinas. JURNAL SIMBOLIKA: Research and Learning in Communication Study, 6(2), 174-189. https://doi.org/10.31289/ simbollika.v6i2.4135

Hepler, J. P. (2012). Documentary discovery and advocacy: A contextual and creative perspective [WAKE FOREST UNIVERSITY]. In ProQuest Dissertations and Theses (Issue May). http://hdl.handle. net/10339/37244

Hidayat, H. N., Sudardi, B., Widodo, S. T., \& Habsari, S. K. (2021). Menggali Minangkabau dalam film dengan miseen-scene. ProTVF, 5(1), 117. https://doi. org/10.24198/ptvf.v5i1.29433

Hong, X., \& Duan, C. (2020). The Construction of Sichuan Image under Multimodal Visual Grammar-Taking the Documentary "Aerial China (Sichuan)" as an Example. Open Journal of Social Sciences, 08(12), 108-120.

https://doi.org/10.4236/ jss. 2020.812010

Jatmiko, M. I. (2019). Hibridisasi Masyarakat Tionghoa di Kecamatan Lasem PascaReformasi. Umbara, 4(2), 101. https://doi. org/10.24198/umbara.v4i2.21697

Kadek Yudiana, I., Miskawi, \& Pardi, W. I. (2017). Analisis Kerukunan Antar Umat Beragama Pada Masyarakat Multikultur Di Ujung Timur Pulau Jawa (Studi Kasus Di Desa Patoman, Blimbingsari, Banyuwangi, Jawa Timur). Jurnal Ilmu Sosial Dan Humaniora, 6(2), 147-158. https://doi.org/ http://dx.doi.org/10.23887/jish-undiksha. v6i2.12033

Kishore, S., \& Stiff, A. (2020). Co-constructed Documentary Film: collaboration, dialogue, and performance in researching gender and contemporary art in Vietnam. Feminist Media Studies, 00(00), 1-19. https://doi.or g/10.1080/14680777.2020.1793793

Kristianto, B. R. D., \& Marta, R. F. (2019). Monetisasi Dalam Strategi Komunikasi Lintas Budaya Bayu Skak Melalui Video Blog Youtube. LUGAS Jurnal Komunikasi, 3(1), 45-56. https://doi.org/https://doi. org/10.31334/ljk.v3i1.415

Kuo, Y.-T. (2012). Social Responsibility and Aesthetics: The Function of Documentary Filmmaking in Contemporary Taiwan (Issue November) [Griffith University]. https://www120.secure.griffith.edu. $\mathrm{au} / \mathrm{rch} /$ file/6ce $8048 \mathrm{a}-418 \mathrm{a}-4$ f8b-b1d44b0f3c79ce74/1/Kuo_2013_02Thesis.pdf

Kurnianto, R. D., \& Iswari, R. (2019). Bentuk Toleransi Umat Beragama Islam dan Konghucu di Desa Karangturi, Kecamatan Lasem, Kabupaten Rembang. Solidarity: Journal of Education, Society and Culture, 8(1), 572-586. https://journal.unnes.ac.id/ sju/index.php/solidarity/article/view/31305 Latukolan, J. J., Marta, R. F., \& Engliana, E. 
(2021). When Words Matter: Language Choices and Brand Building on Two Global Coffee Shop Retail Brands in Indonesia. Budapest International Research and Critics Institute (BIRCIJournal): Humanities and Social Sciences, 4(2), 2899-2906. https://doi.org/10.33258/ birci.v4i2.1974

Littlejohn, S. W., \& Foss, K. A. (2009). Encyclopedia of Communication Theory. Sage Publications.

Lumampauw, A., Marta, R. F., Nugroho, Y., Sandel, T. L., \& Lie, S. (2021). The art of honing the conscience through bukalapak ads : barongsai Indonesia, juara hati membangun bangsa. International Journal of Visual and Performing Arts, 3(1), 9-21. https://doi.org/https://doi.org/10.31763/ viperarts.v3i1.342

Mahlil, M. (2020). Film Bernuansa Budaya Aceh sebagai Media Dakwah (Analisis Semiotika Pada Film Dokumenter Dalae dan Film Dokumenter Beut Ba'da Meugreb Produksi Aceh Documentary Banda Aceh). Jurnal AL-IJTIMAIYYAH: Media Kajian Pengembangan Masyarakat Islam, 6(1), 107-131. https://doi.org/10.22373/alijtimaiyyah.v6i1.6715

Marta, R. F., \& Robin, P. (2019). Kebahasaan Sinematik Bernuansa Pluralitas Dalam Iklan Bni Taplus Anak. Communication, 10(1), 16. https://doi.org/10.36080/comm. v10i1.810

Mawalia, K. Al, \& Sanityastuti, M. S. (2020). Komunikasi Antar Budaya Madura dan Yogyakarta (Studi Etnografi Adaptasi Speech Code Mahasiswa Madura pada Masyarakat Yogyakarta). Panangkaran: Jurnal Penelitian Agama Dan Masyarakat, 3(2), $\quad 169 . \quad$ https://doi.org/10.14421/ panangkaran.2019.0302-02
Mliless,M.,\&Azzouzi,L.(2020).Environmental Discourse in Moroccan Eco-documentary: The decryption of Scientists' Narratives. International Journal of Language and Literary Studies, 2(1), 199-217. https://doi. org/10.36892/ijlls.v2i1.201

Nafie, J. A. (2020). Pemaknaan Profesi Perempuan Dalam Video Musik Lokal Di Nusa Tenggara Timur. Jurnal Communio : Jurnal Jurusan Ilmu Komunikasi, 9(1), 1538-1563. https://doi.org/10.35508/ jikom.v9i1.2311

Novtarianggi, G., Sulanjari, B., \& Alfiah, A. (2020). Hibriditas, Mimikri, dan Ambivalensi dalam Novel "Kirti Njunjung Drajat” Karya R.TG Jasawidagda Kajian Postkolonialisme. JISABDA: Jurnal Ilmiah Sastra Dan Bahasa Daerah, Serta Pengajarannya, 2(1), 27-34. https://doi. org/10.26877/jisabda.v2i1.6220

O'Halloran, K. L. (2008). Systemic functionalmultimodal discourse analysis (SF-MDA): Constructing ideational meaning using language and visual imagery. In Visual Communication (Vol. 7, Issue 4). https:// doi.org/10.1177/1470357208096210

O’Halloran, K. L. (2011). Multimodality Discourse Analysis. In Continuum Companion to Discourse Analysis (pp. 120-137). K. Hyland and B. Paltridge. http://multimodal-analysis-lab.org/_ docs/pubs14-OHalloran\%28in press 2011\%29-Multimodal_Discourse Analysis.pdf

Perdana, D. D. (2020). Reception Analysis of Related Audience by Watching "Sexy Killers" the Documentary Film. 423(October 2019), 86-98. https://doi. org/10.2991/assehr.k.200325.009

Peterson, M., Wise, K., Lindgren, R., Cox, D., \& Mathayas, N. (2015). Understanding and 
Implementing Visual Metaphor. Illinois Learning Sciences Design Initiative, 1(1), 1-33. http://textimage.org/indices/pdf/ Understanding-Visual-Metaphor.pdf

Premaratna, N. (2021). Dealing With Sri Lanka's Demons: Using Documentary Film for Peacebuilding. Journal of Peacebuilding \& Development, 154231662098575. https:// doi.org/10.1177/1542316620985756

Rosenthal, A., \& Eckhardt, N. (2016). Writing, directing, and producing documentary films and digital videos. In Writing, Directing, and Producing Documentary Films and Digital Videos. Southern Illinois University Press.

Saleh, A. A., Abdulkareem Rasul, K., \& Fero, K. (2020). Representation of ISIS actions in Television Documentary: Integrating storytelling into Multimodal Discourse Analysis. April. https://doi. org/10.33422/2nd.icfss.2019.12.937

Sasongko, Y. P. D., \& Marta, R. F. (2018). Ekspresi Identitas Melalui Relasi Ayah Dan Anak Pada Iklan Youtube Grab Official. Bricolage: Jurnal Magister Ilmu Komunikasi, 4(02), 118. https://doi. org/10.30813/bricolage.v4i02.1656

Setiono, B. G. (2008). Tionghoa Dalam Pusaran Politik. TransMedia.

Setyaningsih, R. (2020). Akulturasi Budaya Jawa sebagai Strategi Dakwah. Ri'ayah: Jurnal Sosial Dan Keagamaan, 5(01), 73. https://doi.org/10.32332/riayah.v5i01.2304
Sudarto, A. D., Rembang, M., \& Senduk, J. (2015). Analisis Semiotika Film “Alangkah Lucunya Negeri Ini." ACTA DIURNA Komunikasi, IV(1), 2.

Sugiyanto, B. A. W. (2021). Hibriditas Budaya Jawa dan Budaya Barat di Museum Keraton Yogyakarta. Jurnal Ilmiah Multimedia Dan Komunikasi, 6(1), 1-11. http://ojs.mmtc. ac.id/index.php/jimk/article/view/107

Sulistyo, H., Binangun, P. S., \& Sartika, E. (2020). Hibriditas, Nation, dan Aspek Nostalgis RepresentasiPascakolonial dalam Lirik Lagu-Lagu Jawa Suriname. Jurnal Kawistara, 10(3), 352. https://doi.org/ https://doi.org/10.22146/kawistara.58521

Sya, M., Marta, R. F., \& Hadi, I. P. (2020). Refleksi Pluralisme Melalui Film Animasi $\mathrm{Si}$ Entong Sebagai Identitas Budaya Indonesia. Jurnal Riset Komunikasi, 3(1), 18-33. https://doi.org/10.24329/jurkom. v3i1.102

Umarela, F. H., Dwityas, N. A., \& Zahra, D. R. (2020). Representasi ideologi supremasi kulit putih dalam iklan televisi. ProTVF, 4(1), 64. https://doi.org/10.24198/ptvf. v4i1.25172

Utami, M., \& Endah Sokowati, M. (2021). Konstruksi Identitas Global Dan Lokal Dalam Majalah Gogirl!: Sebuah Hibriditas (Analisis Semiotik Majalah Gogirl! Edisi 101 Bulan Juni Tahun 2013). Jurnal Komunikasi, 15(2), 91-108. https://doi. org/10.20885/komunikasi.vol15.iss2.art2 